\title{
Haemophilia in the developing countries: the Iranian experience
}

Peyman Eshghi ${ }^{1}$, Mitra Mahdavi-Mazdeh², Mehran Karimi ${ }^{3}$, Mohammad Aghighi $^{4}$

\author{
${ }^{1}$ Paediatric Haematology and Oncology, Shahid Beheshti University of Medical Sciences; \\ Iranian Blood Transfusion Organization, Tehran, Iran \\ ${ }^{2}$ Management Center of Transplantation and Special Diseases (MCTSD-MOH), Tehran \\ University of Medical Sciences, Tehran, Iran \\ ${ }^{3}$ Pediatric Hematology and Oncology, Hematology Research Center, Shiraz University \\ of Medical Sciences, Shiraz, Iran \\ ${ }^{4}$ Management Center of Transplantation and Special Diseases (MOH), Tehran, Iran
}

Submitted: 21 July 2008

Accepted: 6 November 2008

Arch Med Sci 2010; 6, 1: 83-89

DOI 10.5114/aoms.2010.13512

Copyright ( 2010 Termedia \& Banach

\section{Abstract}

Introduction: Management of haemophilia and inherited bleeding disorders is a major challenge especially in developing countries, because of a shortage or absence of products, the cost and the infrastructural health problems. Development of local expertise which results in an improved outlook and reduction in mortality and morbidity in these countries can be helpful for advocators in other developing countries. However, very little information on demography and organizational models for haemophilia care in developing countries are available in the literature. Our aim is a comprehensive report of haemophilia status and its management in Iran.

Material and methods: The Management Center of Transplantation and Special Diseases (MCTSD) of the Ministry of Health of Iran decided to carry out a complete review and compilation of all of the published or available data about patients with haemophilia (PWH) in Iran: their health status, their management planning, organizations, treatment products, facilities and care problems during 2007.

Results: 6496 patients with congenital bleeding disorders were registered. Most of them had haemophilia A and B and von Willebrand disease (vWD). However, rare bleeding disorders are seen more than expected. Inhibitor development is $14-28 \%$. There are different data about virological status of PWH. Factor products and facilities are fairly available with more than 1.5 units per capita of inhabitant factor consumption.

Conclusions: A national formulary based on facilities of the country should be considered and followed by collaboration among the Ministry Of Health, universities and non-governmental organizations.

Key words: Iran, haemophilia care, developing world.

\section{Corresponding author:} Peyman Eshghi, MD Department of Pediatric Hematology and Oncology Mofid Children's Hospital Shariati Ave Tehran, Iran

Post code: $15468-15514$ Phone: + $982122227020-9$

Fax: +98 2122220254 E-mail: eshghi@ibto.ir

\section{Introduction}

New advances in haemophilia treatment such as virally safe factor concentrates and a comprehensive approach to patients have improved the life expectancy as well as the quality of life for haemophiliacs, especially in the last 3 decades $[1,2]$. However, treatment options vary around the world. There is wide variability not only in the types of products used (plasma, cryoprecipitate, plasma derived factor concentrates and recombinant factor concentrates) but also in the doses administered 
(minimal to very high) for similar indications [3-5]. In developed countries, accurate diagnosis and treatment based on early recognition of the disease, carrier detection, antenatal diagnosis, standard treatment, prophylaxis, home therapy, early treatment of bleeding episodes, sustained replacement therapy with virally safe clotting factor concentrates, and establishment of comprehensive care centres with a multidisciplinary team resulted in significant effects on patients' general health, quality of life and survival. Also the haemophilia community request resulted in receipt of support for networks of haemophilia treatment centres (HTCs) from governments [6, 7].

At the same time, in the developing world (with almost $80 \%$ of the haemophilia population, who benefit from only $20 \%$ of the world's total haemophilia care budget), development of local expertise resulted in an improved outlook and reduction in mortality and morbidity in spite of a shortage or absence of factor products $[8,9]$. However, very little information on demography and organizational models for haemophilia care in developing countries, and also on the types of products being used for factor replacement and the doses being administered for control or treatment of bleeding in different countries, are available in the literature [5, 10-12]. In this study the current situation and the developed plan for the
"Hemophilia Care Program in Iran" will be reviewed to document these data in comparison with other countries.

\section{Iranian Haemophilia Services Organization}

Iran is a Middle Eastern country comprising 30 provinces and covering an area of 1.648 million square kilometres. The population is around 70 million, life expectancy is 69.96 years [13] and the gross national product (GNP) is reported to be 2767 US\$ per capita in 2005 [14].

Haemophilia management in Iran was organized in Imam Khomeini hospital of Tehran University of Medical Sciences in the early 1960s, and it has been the main centre for haemophilia care until now. Although the Ministry of Health $(\mathrm{MOH})$ has been the sponsor of management of haemophilia during the last 40 years, a turning point came in 2001 , when the $\mathrm{MOH}$ established official relations with haemophilia and thalassaemia treatment and management programmes in addition to dialysis and transplantation through the Management Center of Transplantation and Special Diseases (MCTSD) (Figure 1). The organization was responsible not only for the provision of necessary products and services through the undersecretary of Food and Drugs in the Ministry of Health but also in policy making and strategic planning to achieve



Figure 1. $\mathrm{MOH}$ Organization 
and establish higher standards of treatment. Throughout 2001-2003, a major function of the centre was to assess the situation of treatment and correction of data. Recognizing the importance of a national haemophilia programme, MCTSD created a national haemophilia committee, composed of physicians who were experts in the treatment of haemophilic patients. As recommended by the World Federation of Hemophilia (WFH), the mission of this committee was the introduction of specific and practical programmes to be used as tools to further treatment of haemophilia and related disorders [15], which covered sensible dosing and equitable distribution of resources to gain the maximum benefit from scarce resources.

In Iran, at present, 41 medical universities are responsible for implementing different treatment and prevention programmes of the Ministry of Health in all the provinces. In each university, one is to oversee and coordinate affairs of haemophilia, thalassaemia, haemodialysis and transplanted patients in different wards which are covered by that special university and are in direct contact with the MCTSD. The data gathering for the national registry is done by these teams for the centre for administrative issues. Collection of data is the mandatory tool, and the budget designation is on the basis of correct information. After 3 years, the MCTSD with participation of pundits is going to develop a "comprehensive national database" which will be offered on-line to all universities in 2007.

There are also several non-governmental organizations, engaged in the field of haemophilia in Iran, such as the Iranian Hemophilia Society, the Iranian Pediatric Hematology and Oncology Society (IPHOS), and the Charity Foundation for Special Diseases. Haemophilia care units which are affiliated to the $\mathrm{MOH}$ in Iran in many provinces are managed with such collaboration among them, universities' staffs and hospitals being under the provision of the MCTSD.

Non-profit organizations play an important role in solving public problems, creating more competitive environments for securing charitable support and strengthening public infrastructures. The Iranian Hemophilia Society (IHS) was established in 1967 by government authorities $[16,17]$. Their main objectives were social support and contribution in education of haemophilic patients (in face-to-face classes or through brochures and CDs). They have 21 branches with 100 staffs throughout the country [17]. They have also developed a patient registry database to collect information about haemophiliac patients and their families [18]. They are also committed to improving patients' access to treatment facilities and have constructed a part-time out-patient clinic with a well equipped coagulation laboratory in Tehran since 2001.

\section{Material and methods}

In this study, the MCTSD of the MOH of Iran, which has the main responsibility for the treatment of haemophilia through 41 medical universities and their related clinics around the country (as the main and original sources of haemophilia data in Iran), carried out a complete review and gathered all of the published or available data about patients with haemophilia (PWH) in Iran: their health status, their management planning, organizations, treatment and care problems during 2007.

\section{Results and Discussion}

\section{Frequency and prevalence}

There are 6496 cases with congenital bleeding disorders who were registered by the $\mathrm{MOH}$ of Iran by December 2006, so the prevalence was estimated at about 9.18 per 100,000. Among them, there are 3957 (61\%) FVIII deficiency haemophilia A (frequency of severe, moderate and mild haemophilia A were 47, 33 and 20\% respectively). The prevalence of registered congenital bleeding disorders - including congenital platelet function abnormalities [19] in Iran is shown in Figure 2. Also, regarding the poor availability of diagnostic facilities in most of the centres, the majority of registered cases of von Willebrand Disease (VWD) are symptomatic with frequent medical therapies (mainly type 3) [20], and definite classification for most of the others has not been possible. Although according to the WFH's survey, the rate of diagnosis of persons with haemophilia is directly related to the economic income of the region, it is worth noting that the number of detected haemophilia $A$ and $B$ ( $~ 65$ cases per million inhabitants) cases is much higher than expected based on the GNP of Iran in 2005 (2767\$) (Table I) [12, 14, 21].

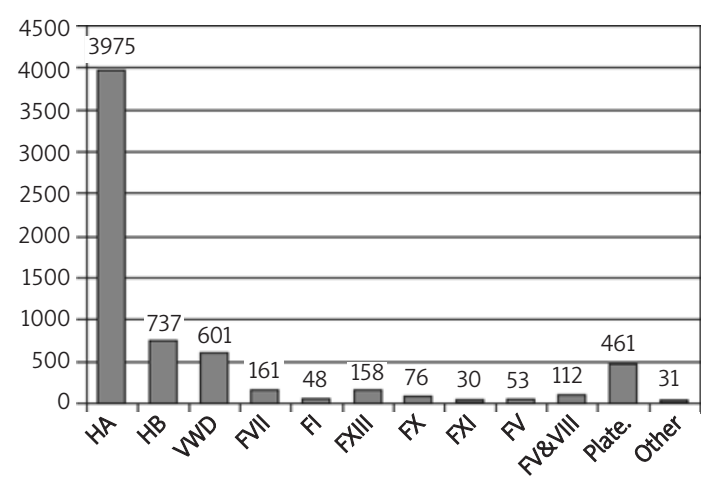

Figure 2. Frequency of congenital bleeding disorders in Iran 
Table I. Relationship between gross national product (GNP) and detected haemophilia patients

\begin{tabular}{|lc|}
\hline GNP & $\begin{array}{c}\text { Detected haemophilia cases } \\
\text { per } 1000000 \text { inhabitants }\end{array}$ \\
\hline < US\$ 2000 & 17 \\
\hline US\$ 2000 to US\$ 10000 & 35 \\
\hline$>$ US\$ 10000 & 61 \\
\hline
\end{tabular}

Report on the WFH Global Survey 2001

\section{Inhibitor development}

Approximately $15-35 \%$ of patients with severe haemophilia $A$ in western countries develop inhibitors [22, 23]. The prevalence of inhibitors in haemophilia A patients in developing countries has not been studied extensively [24, 25]. In Iran, there are only two studies considering the prevalence of inhibitor development in haemophilia A. Sharifian et al. reported 184 patients with inhibitor out of $1280 \mathrm{HA}$ registered cases in Tehran University of Medical Sciences (14\%); among them 41 cases (3\%) were high responders. Inhibitor developed in 22, 9.4 and $3.5 \%$ of severe, moderate and mild HA respectively [26]. In another study, 100 cases out of 355 patients $(28.1 \%)$ from six main haemophilia care centres in the east and south of Iran in 2005 had developed factor VIII inhibitor; among them 14 cases (4\%) were high responders [27]. The MCTSD is going to establish a routine screening test in all of the centres by improving their diagnostic facilities.

\section{Blood-borne infections}

Another important issue is virological status in haemophiliacs. Hepatitis C virus (HCV) is the current major virological problem in haemophiliac patients. Since 1995, more careful donor selection and pretransfusion screening of blood donors for anti-HCV has been implemented in all blood banks. According to unpublished official data of the MCTSD from 9 medical universities around Iran, 773 out of 3282 cases with all congenital bleeding disorders were anti-HCV positive. The prevalence of HCV infection in Iranian haemophilic patients has been reported from $15.6 \%$ in Fars, a southern district of Iran, to $76.7 \%$ in North-West Iran in different studies, as reviewed by Allavian et al. [28]. The prevalence of HBS-Ag positive cases has been reported in $<1 \%$ (2/277), 2.8\% (5/171), 27\% (27/101) and 4.9\% (4/81) of patients in different studies [29-32]. The overall expected prevalence of $\mathrm{HCV}$ Ab positivity in patients with haemophilia in Iran is $21 \%$, which in comparison with some other countries is low [33-37]. During winter 2006 to 2007, 400 haemophiliacs with HCV infection were treated with pegylated interferon $\alpha$ alone or in combination with ribavirin by the $\mathrm{MOH}$ [38]. The prevalence of HIV positive haemophiliac patients has been reported as $0.36 \%$ (1/277), $2.3 \%$ (4/176) and 19\% (69/368) in different groups and in different periods of time [29-31, 39].

\section{Quality of life}

The most common symptoms influencing the quality of life in Iran [40] and other developing countries are still haemarthrosis, haematomas and epistaxis [10-12]. Fortunately, in last decade, chemical and radioisotopic synovectomy have been performed successfully in Imam Khomeini Hospital between 2002 and 2006. Mortazavi et al. performed 66 radioisotopic synovectomy procedures in 53 patients. It effectively reduced the intra-articular bleeding rate and factor concentrate use [41].

\section{Treatment and diagnostic facilities}

\section{Transfusion and blood bank}

During the 1960s, Iranian haemophilic patients were treated mainly with plasma supplied by commercial agents who relied mostly on paid blood donors. After establishment of the Iranian Blood Transfusion Organization (IBTO) in 1974 as a governmental non-profit organization for centralized and scientific activities in transfusion, cryoprecipitate and fresh frozen plasma were available gradually for them [42]. In order to provide a safe plasma product for them, in addition to strict donor selection, donated blood underwent serologic tests for HBV, HCV (since 1995), HIV and syphilis. The IBTO is now considering implantation of a nucleic acid test (NAT) system in its screening protocol [42].

In order to supply the Iran pharmaceutical market with plasma derived products, the IBTO started a toll fractionation programme in 2004 . After verification of the quality system of Iranian blood collection centres by the Paul-Ehrlich Institute (as a reputable EU authority) in 2005, toll fractionation of about 70,000 I of plasma in France and Germany to $300 \mathrm{~kg}$ of IVIG, 10 MIU FVIII, 14 MIU FIX, and $1800 \mathrm{~kg}$ albumin has been established [42, 43].

\section{Products and protocols}

Over the past 2 decades, $\mathrm{MOH}$ has been responsible for the acquisition and distribution of concentrated factor products in Iran. These products include plasma derived factor VIII concentrates (FVIII: C) and factor IX concentrates (FIX: C), prothrombin complex (PCC), activated PCC (APCC), and recombinant FVIla (and recently VWF) concentrates and subcutaneous desmopressin for 2007 (Figure 3). After establishment of the MCTSD in the early 2000s, a regular programme has recently been started which planned the acquisition of concentrated factor as IU per patient per year and initiated distribution to the various states 


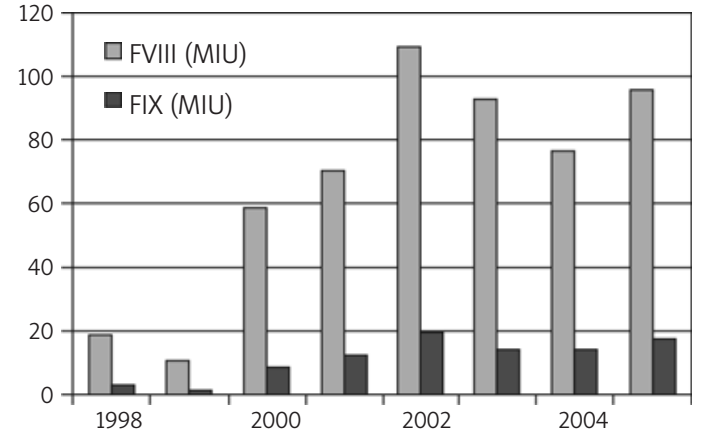

Figure 3. Number of units of factor concentrates purchased per year by Ministry of Health

according to the number of patients registered in each state. Recently a national scientific and cost-effective formulary has been prepared by the Thalassemia and Hemophilia Committee of the MCTSD according to recommendations of the WFH and reliable international references [2, 8, 10, 15, 44, 45].

In this manner, although the total health expenditure of GDP is 6\% [7] in 2006 the budget designation for importation of coagulating factors was about $50,000,000$ US\$ $(20 \%$ of the whole subsidy budget of the Ministry of Health) and factor VIII was supplied at the rate of 1.5 units per capita of inhabitant (and 2 units per capita of inhabitant in 2007), in contrast with many other developing countries. From March 2006 to March 2007, the reported consumption of factor concentrates nationwide was: FVIII: C, 107500000 IU; FIX: C, $17000000 \mathrm{IU}$; APCC $3250000 \mathrm{IU}$; and rFVIIa $46800 \mathrm{mg}$. The total cost of care of patients including products, routine diagnostics and treatment services are paid by the insurance system and the Ministry of Health in Iran. In one study in the Fars province of Iran, the factor cost was $99 \%$ of the total cost of care [46], which is high in comparison with the USA, UK and Italy $(72,29$ and $32 \%$ respectively) $[47,48]$.

Although on-demand therapy is the current treatment strategy in Iran, it seems that it is time to shift from on-demand to a prophylactic programme or home therapy and better services and follow-ups by establishing comprehensive care centres (CCC) all over the country. At the first step, it would be done as a pilot study in some provinces which have expert haematologists and CCCs. A trial programme for home therapies and carrier detection in haemophilia families was set up in Esfahan Province by the Genetic Department of the Center for Disease Control of the $\mathrm{MOH}$ in January 2007. It has also been underway in Shiraz Hemophilia Center since 2004. The last but not the least valuable step is developing comprehensive care, followed through education courses for health care professionals who are in centres in service of
Table II. Available diagnostic facilities in coagulation laboratory of IBTO (2006)

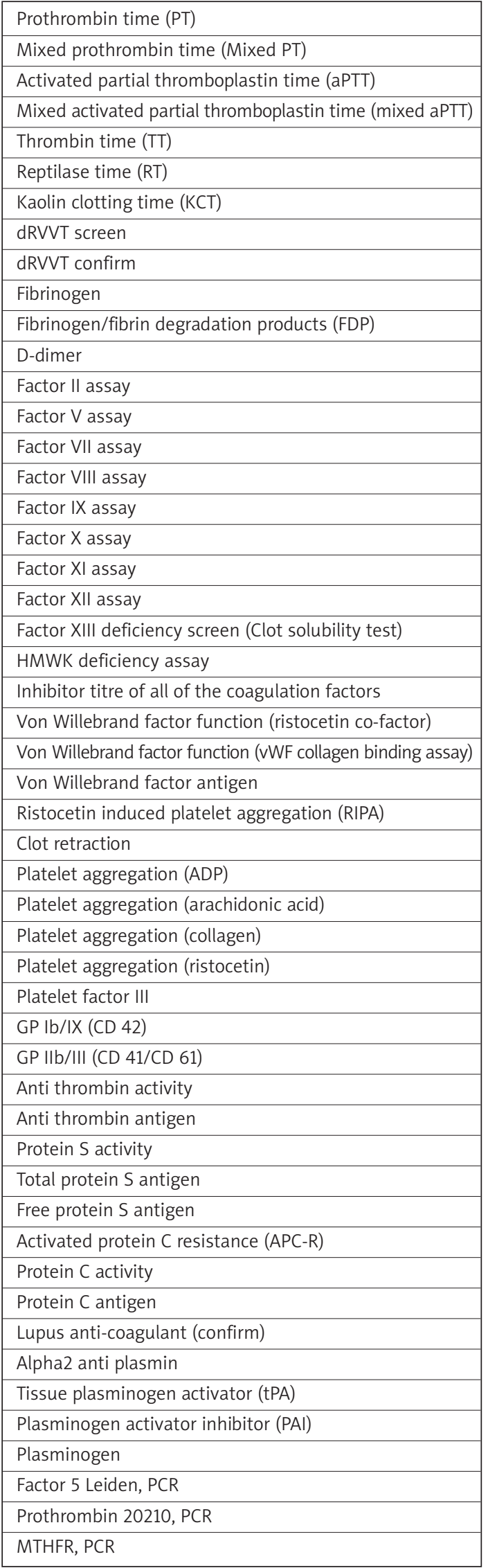


patients. The guidelines have been published by the MCTSD and officially have been sent to universities to be prepared for them.

Surgical interventions in Iranian patients with haemophilia $(\mathrm{PWH})$, like many others in the developing world, are difficult in the setting of limited availability of factor concentrates on one hand and lack of established international guidelines for factor concentrate prophylaxis for PWH undergoing surgery on the other hand. These recommendations were not established based on large clinical trials and fail to define the safe lower limit of factor concentrate prophylaxis for surgery [4]. Whenever the factor supply is in acceptable amounts for elective surgery (especially orthopaedic surgery and circumcision), it is officially announced.

\section{Diagnosis and prevention}

Diagnostic facilities have grown up around the country and now at least 3 well equipped special coagulation and molecular genetics laboratories with expert staffs exist in Iran. The current facilities of the IBTO coagulation laboratory are demonstrated in Table II.

Prenatal diagnosis (PND), a young programme, is an important issue in the comprehensive care of haemophiliacs. As a consequence of technological progress made in this field in Iran, especially during the last 3 years [49], the early detection of an affected fetus through diagnosis of families with a diseased child to reduce incidence with a chance to terminate pregnancy is a young programme in the country. There are two main limitations in this issue. The first is that most Iranians were not familiar with the possibilities afforded by PND for haemophilia [50]. The second is that although there are some passed fatwas (a fatwa is a religious opinion about whether an action is permissible, prohibited, obligatory or disliked) from religious scholars permitting abortion in positive cases, it is not yet legal. The subject is being followed by the $\mathrm{MOH}$.

In conclusion, we argue that treatment of haemophiliacs in the developing countries should be based on at least two aspects. First, a national formulary based on facilities of the country should be considered and followed. As a result, the minimum acceptable standards can be achieved more easily and the next steps become practical. Heterogenicity is risky for any strategic planning. Secondly, cooperation among medical personnel, the government, NGOs and scientific boards must be promoted to establish successful care.

\section{Acknowledgments}

We would like to thank Shiraz University of Medical Science for its financial support, Dr. Davood Mehrabani at the Center for Development of Clinical
Research of Nemazee Hospital for editorial assistance, and also Shirin Parand at the Hematology Center for editorial assistance.

\section{References}

1. Giangrande PL. Blood products for hemophilia: past, present and future. BioDrugs 2004; 18: 225-34.

2. Chuansumrit A. Treatment of haemophilia in the developing countries. Haemophilia 2003; 9: 387-90.

3. Mannucci PM. Hemophilia: treatment options in the twenty-first century. J Thromb Haemost 2003; 1: 1349-55.

4. Mathews V, Viswabandya A, Baidya S, et al. Surgery for hemophilia in developing countries. Semin Thromb Hemost 2005; 31: 538-43.

5. Bolton-Maggs PH. Optimal haemophilia care versus the reality. Br J Haematol 2006; 132: 671-82.

6. Smith PS, Levine PH. The benefits of comprehensive care of hemophilia: a five-year study of outcomes. Am J Public Health 1984; 74: 616-7.

7. Jones P. Hemophilia home therapy. Homeostasis 1992; 22: 247-50.

8. World Federation of Haemophilia. Annual Report 200. Montreal, Canada: WFH, 2001.

9. Srivastava A, Chuansumrit A, Chandy M, Duraiswamy G, Karagus C. Management of haemophilia in the developing world. Haemophilia 1988; 4: 474-80.

10. Srivastava A, You SK, Ayob Y, et al. Hemophilia treatment in developing countries: products and protocols. Semin Thromb Hemost 2005; 31: 495-500.

11. Ghosh K. Management of haemophilia and its complications in developing countries. Clin Lab Haematol 2004; 26: 243-51.

12. Antunes SV. Haemophilia in the developing world: the Brazilian experience. Haemophilia 2002; 8: 199-204.

13. World factbook/Iran:www.CIA.org.

14. IMF GDP per capita ranking: www.imf.org.

15. Giangrande PL, Black C. World Federation of Haemophilia programs in developing countries. Semin Thromb Hemost 2005; 31: 555-60.

16. Available at: www.hemophilia.org.ir.

17. Bghaiepour A. Hemophilia in IRAN. Regional Hemophilia Seminar, April 2004, Mahmood Abad, Iran.

18. Tchupan A. Developing a national patient registry Iranian experience. International meeting on challenges on Hemophilia treatment in developing countries. Feb. 5-7 2006, Tehran, Iran.

19. Toogeh G, Sharifian R, Lak M, Safaee R, Artoni A, Peyvandi F. Presentation and pattern of symptoms in 382 patients with Glanzmann thrombasthenia in Iran. Am J Hematol 2004; 77: 198-9.

20. Lak M, Peyvandi F, Mannucci P. Clinical manifestations and complications of child birth and replacement therapy in 385 Iranian patients with type 3 Von Wilbrand disease. Br J Haematol 2000; 111: 1236-9.

21. World Federation of Haemophilia. Report on the WFH Global Survey 2001. Montreal, Canada: WFH, 2001.

22. Tizzano EF, Altisent C, Domenech M, Cornet M, Tusell J, Baiget M. Inhibitor development in hemophilia A patients with inversion of the intron 22 of the factor VIII gene. Thromb Haemost 1996; 76: 125-6.

23. Vermylen J. How do some hemophiliacs develop inhibitor? Haemoplilia 1998; 4: 538-42.

24. Ghosh K, Shetty S, Kulkarni B, et al. Development of inhibitors in patients with haemophilia from India. Haemophilia 2001; 7: 273-8. 
25. Kavakli K, Gringeri A, Bader R, Nisli G, Polat A, Aydinok Y. Inhibitor developments and substitution therapy in a developing country: Turkey. Haemophilia 1998; 4: 104-8.

26. Sharifian R, Hosseini M. Prevalence of inhibitor in 1280 cases with Hemophilia. Acta Medica Iranica 2003; 41: 66-8.

27. Eshghi $\mathrm{P}$, Jazebi $\mathrm{M}$, Hoorfar $\mathrm{H}$, et al. Multicentric screening of factor VIII inhibitor in 355 Hemophilia a patients in IRAN 2005. Haemophilia 2006; 12: 60.

28. Alavian SM, Adibi P, Zali MR. Hepatitis C virus in Iran: epidemiology of an emerging infection. Arch Iran Med 2005; 8: 84-90.

29. Sharifi-Mood B, Eshghi P, Sanei-Moghaddam E, Hashemi M. Hepatitis B and C virus infections in patients with hemophilia in Zahedan, Southeast Iran. Saudi Med 2007; 28: 1516.

30. Alavian SM, Ardeshiri A, Hajarizadeh B. Prevalence of HCV, HIV and HBS-Ag among Hemophiliac patients. Hakim Research J 2003; 6: 45-51.

31. Karimi M, Ghavanini AA. Seroprevalence of HBsAg, antiHCV, and anti-HIV among haemophiliac patients in Shiraz, Iran. Haematologia (Budap) 2001; 31: 251-5.

32. Mansour-Ghanaei F, Fallah MS, Shafaghi A, YousefiMashhoor $M$, et al. Prevalence of hepatitis B and C seromarkers and abnormal liver function tests among hemophiliacs in Guilan (northern province of Iran). East Mediterr Health J 2005; 11: 372.

33. Fontes EM, Amorim L, Carvalho SM, Farah MB. Hemophilia care in the state of Rio de Janeiro, Brazil. Rev Panam Salud Publica 2003; 13: 124-8.

34. Chakrabarti S, Pradhan P, Roy A, Hira M, Bandyopadhyay G, Bhattacharya DK. Prevalence of anti HCV, HBsAg and HIV antibodies in high risk recipients of blood and blood products. Indian J Public Health 2006; 50: 43-4.

35. Federici AB, Santagostino E, Rumi MG, et al. The natural history of hepatitis $C$ virus infection in Italian patients with von Willebrand's disease: a cohort study. Haematologica 2006; 91: 503-8.

36. Silva LK, Silva MB, Lopes GB, et al. Prevalence of hepatitis C virus infection and HCV genotypes among hemophiliacs in the State of Bahia, Northeastern Brazil: analysis of serological and virological parameters. Rev Soc Bras Med Trop 2005; 38: 496-502.

37. Al-Kubaisy WA, Al-Naib KT, Habib MA. Prevalence of $\mathrm{HCV} / \mathrm{HIV}$ co-infection among Haemophilia patients in Baghdad. East Mediterr Health J 2006; 12: 264-9.

38. Alavian SM. Control of hepatitis $C$ in Iran: vision and missions. Hepatitis 2007; 7: 57-8.

39. Houri R, Taroyan S, Jalali S, Keyhani M. A study on Hiv-1 infection amongst Hemophiliacs in Iran. Int Conf Aids 1989; 5: 1007 (Abstract No. T.G.P.20).

40. Hoorfar H, MobarakyG. Quality of life in severe hemophilia in Esfahan. Haemophilia 2006; 12: 122.

41. Mortazavi SM, Asadollahi S, Farzan M, et al. (32)P Colloid radiosynovectomy in treatment of chronic haemophilic synovitis: Iran experience. Haemophilia 2007; 13: 182-8.

42. Cheraghali AM. Availability of blood components and plasma derived medicines in Iran. Transf Apheres Sci 2007, 37: 3-7.

43. Cheragh-ali A. Plasma fractionation in Iran, international meeting on challenges on hemophilia treatment in developing countries. Feb. 5-7 2006, Tehran, Iran.

44. Chandy M. Treatment Options in the Management of Hemophilia in Developing Countries. Treatment of Hemophilia. December 2005, Number 37.

45. Kasper CK. Products for clotting factor replacement in developing countries: seminars in Thrombosis \&
Hemostasis. Hemophilia and von Willebrand Disease in Developing Countries. 2005; 31: 507-12.

46. Karimi M. Health status and costs of care in Iranian hemophilic patients, International meeting on challenges on hemophilia treatment in developing countries. Feb. 5-7 2006, Tehran, Iran.

47. Globe DR, Cunningham WE, Andersen RM, et al. The Haemophilia Utilization Group Study (Hugs): determinants of costs of care in persons with haemophilia. Haemophilia 2003; 9: 325-31.

48. Schramm W, Royal S, Kroner B, et al. Clinical outcomes and resource utilization associated with haemophilia care in Europe. Haemophilia 2002; 8: 33-43.

49. Rastegar Lari G, Enayat MS, Arjang Z, Lavergne JM, Ala F. Identification of Intron 1 and 22 inversion mutations in the factor Viii gene of 124 Iranian families with severe haemophilia A. Haemophilia 2004; 10: 410-1.

50. Karimi M, Peyvandi F, Siboni S, Ardeshiri R, Gringeri A, Mannucci PM. Comparison of attitudes towards prenatal diagnosis and termination of pregnancy of haemophilia in Iran and Italy. Haemophilia 2004; 10: 367-9. 